\title{
PERCEPÇÃO DOS PROFISSIONAIS DE SAÚDE DA ATENÇÃO BÁSICA DO MUNICÍPIO DE SENHOR DO BONFIM BAHIA: SUPORTE BÁSICO DE VIDA
}

\author{
PERCEPTION OF HEALTH PROFESSIONALS FROM BASIC ATTENTION IN THE \\ MUNICIPALITY OF SENHOR DO BONFIM BAHIA: BASIC LIFE SUPPORT
}

\author{
Agnete Troelsen Pereira Nascimento, Monalisa Batatinha de Castro Silva, Nataly Viviane \\ Maia Gama da Cunha, Júlia Lima da Silva, Paulo Sergio Pereira de Souza
}

UNEB

\begin{abstract}
The aim of this article was to analyze the level of knowledge that primary care health professionals in a municipality in the interior of Bahia have about Basic Life Support, before and after the training is carried out. This is a quantitative, descriptive and exploratory study, carried out with 112 health professionals. The technique used for data collection was the interview, guided by a semi-structured questionnaire, called pre and post-test with objective questions. The results showed that the professionals' knowledge about Basic Life Support is not sufficient to act on the front lines of urgency / emergency units. It is concluded, therefore, that through the results obtained in this research it was possible to verify the importance of continuous training and periodic updating with regard to basic life support, being essential for the approach to patients in cardiovascular arrest. In view of this, the main focus in the treatment of cardiac arrest in adults includes the rapid recognition and immediate provision of quality CPR.
\end{abstract}

Keywords: Nursing, Basic life support, Training.
Resumo

O objetivo do presente artigo foi de analisar o nível de conhecimento que os profissionais de saúde da Atenção Básica de um município no interior da Bahia têm acerca do Suporte Básico de Vida, antes e após a execução da capacitação. Trata-se de um estudo quantitativo, de caráter descritivo e exploratório, realizado com 112 profissionais de saúde. A técnica utilizada para a coleta de dados foi a entrevista, norteada por um questionário semiestruturado, denominado pré e pós-teste com questões objetivas. Os resultados demonstraram que o conhecimento dos profissionais acerca do Suporte Básico de Vida, não são suficientes para atuação na linha de frente das unidades de urgências/emergências. Conclui-se, pois, que por meio dos resultados obtidos nessa pesquisa foi possível verificar a importância de treinamentos contínuos e da atualização periódica no que se refere ao suporte básico de vida, sendo essencial para a abordagem aos pacientes em parada cardiovascular. Diante disso o foco principal no tratamento da parada cardíaca em adultos inclui o reconhecimento rápido e o fornecimento imediato de Ressuscitação Cardiopulmonar de qualidade.

Palavras-chave: Enfermagem, Suporte básico de vida, Capacitação. 
Implantado em meio à comunidade onde as ocorrências acontecem com grande frequência, a Unidade Básica de Saúde (UBS) assim como as unidades hospitalares devem estar preparadas para a demanda de seus usuários, dentre os vários acometimentos, destaca-se a Parada Cardiorrespiratória (PCR), sendo ela a ausência repentina da função cardíaca, ocorrendo em sequência à cessação da função de outros órgãos vital devido à falta de oxigenação pela ausência da respiração ${ }^{1}$.

A principal consequência das doenças do aparelho circulatório é a PCR onde a cardiopatia isquêmica se destaca como mais comum causadora de mortes. Dados estatísticos mostram que os homens apresentam uma maior prevalência de desenvolver problemas cardiovasculares comparado às mulheres, entre os fatores de risco estão o tabagismo, sobrepeso, consumo abusivo de bebidas alcoólicas e a inatividade física ${ }^{2}$.

A região Nordeste se destacou com o maior número de óbitos durante os anos de 2006-2016, totalizando $8.066(37,1 \%)$, sendo Pernambuco o representante maior de ocorrência. A região Sudeste com 6.756 (31,1\%) representado por São Paulo, a região Sul com 3.528 (16,2\%), Centro-Oeste com $1.717(7,9 \%)$ e Norte com $1.624(7,4 \%)^{3}$.

Os profissionais de saúde devem estar preparados para reconhecer, por meio da avaliação dos sinais e sintomas de cada faixa etária, os sinais de gravidade. A impressão inicial do paciente em situação de urgência forma uma "fotografia instantânea" mental que possibilita o reconhecimento rápido de instabilidade fisiológica ${ }^{4}$.

A atenção primária é o serviço de atenção à saúde e o que se encontra mais próximo da população devem estar capacitados para prestar um atendimento adequado de acordo com suas demandas 5 . Pelo fato de haver esse contato mais próximo entre unidade e usuário, é notório de que ali haverá atendimento para suprir as necessidades com a vantagem de a equipe da unidade de saúde conhecer toda população adscrita a ela. Diante disso objetivou analisar o nível de conhecimento que os profissionais de saúde da Atenção Básica do município de Senhor do Bonfim/BA têm acerca do Suporte Básico de Vida, antes e após a execução da capacitação.

\section{Metodologia}

Trata-se de um estudo quantitativo, de caráter descritivo e exploratório. Com o objetivo de classificar e analisar um determinado fenômeno, necessitando por isso, do uso de recursos e de técnicas estatísticas. O caráter descritivo se mostra essencial, para que seja possível observar, registrar, analisar e correlacionar fatos encontrados sobre o fenômeno ${ }^{6}$. Já o exploratório visa proporcionar maior familiaridade com o problema com vistas a torná-lo explícito ou a construir hipóteses. Envolve levantamento bibliográfico; entrevistas com pessoas que tiveram experiências práticas com o problema pesquisado; análise de exemplos que estimulem a compreensão ${ }^{7}$.

A coleta de dados foi realizada no Município de Senhor do Bonfim - Bahia, que possui uma população $79.424^{8}$. Possui dezesseis equipes de Programa de Saúde da Família (PSF), que cobre $73,3 \%$ da população local. $O$ estudo foi desenvolvido a partir dos dados oriundos de um pré-teste com questões objetivas, com o propósito de avaliar o nível de conhecimento sobre o assunto, antes de realizar uma capacitação com os profissionais de saúde, com tema proposto: Suporte Básico de Vida na Atenção Básica, com abordagem teórica e prática, ministrada pelo Núcleo de Educação Permanente em Urgência do Serviço de Atendimento Móvel de Urgência (SAMU). Após o curso sucedeu o pós-teste com os mesmos questionamentos do pré-teste, com intuito de observar a efetividade da capacitação ofertada.

$$
\text { A análise dos dados iniciou }
$$
posteriormente à aplicação do pré e pós-teste, no qual serão computados em porcentagem, os erros e acertos, antes e após a capacitação teórico-prática. Por fim, foi feita uma discussão dos dados encontrados, de acordo com a leitura dos autores que discutem acerca da temática abordada na pesquisa.

Os profissionais que aceitaram participar do estudo foram: um Assistente social, três Auxiliares de enfermagem, quatro Auxiliares de saúde bucal, um condutor, 21 Enfermeiros, três fisioterapeutas, um Fonoaudiólogo, 16 Médicos, um Nutricionista, 13 Odontólogos, dois Profissionais de Educação física, e 44 Técnicos de enfermagem do quadro técnico dos PSF's e Núcleo de Assistência à Saúde da Família (NASF), totalizando 112 profissionais. Desse modo, o critério de inclusão consiste em ser profissional de saúde integrante da Atenção Básica do referido município, enquanto o critério de 
exclusão consistiu em ser Agente Comunitário de Saúde.

Foi disponibilizado um Termo de Consentimento Livre e Esclarecido - TCLE, imprescindível em toda a pesquisa que envolve os seres humanos, respeitando a autonomia e a dignidade dos envolvidos, sendo direito do participante tomar conhecimento dos objetivos, justificativa e benefícios resultantes da proposta. Por se tratar de pesquisa que envolve seres humanos, este estudo foi submetido à Plataforma Brasil, mais especificamente ao Comitê de Ética em Pesquisa com Seres Humanos (CEP), a fim de defender os interesses dos participantes do estudo em sua integridade e dignidade, conforme Resolução CNS no 466/12. ${ }^{9}$

\section{Resultados}

Aqui estão descritos a distribuição das questões do pré-teste e pós-testes aplicada aos profissionais de saúde da Atenção Básica (Tabela 1).

Tabela 1 - Questões do pré-teste e pós-testes aplicada aos profissionais de saúde da Atenção Básica.

\section{1 - Com relação à prestação de socorro a uma vítima de parada cardiorrespiratória,} assinale a alternativa correta.

a. A frequência de compressão torácica, em adultos, deve ser de 80 a $100 /$ minuto.

b. O uso de pressão cricóide durante as ventilações, em geral, é recomendado, pois facilita a colocação de uma via respiratória permanente.

c. O procedimento "ver, ouvir e sentir se há respiração" foi abolido da sequência de avaliação da respiração.

d. A RCP em adultos deve ser iniciada com a ventilação de resgate, em vez de compressões torácicas.

e. O socorrista que atua sozinho deve iniciar a RCP com duas ventilações seguidas de trinta compressões, tendo em vista a necessidade de aporte respiratório imediato.

02 - Seguindo os princípios de Primeiros Socorros e as orientações do Suporte Básico de Vida (SBV) da American Heart Association, marque a alternativa CORRETA:

a. A compressão torácica deverá deprimir o tórax entre 5 a $10 \mathrm{~cm}$, realizado.

b. Uma das orientações do SBV da AHA para atendimento a pessoa é de: 1) solicitar auxílio ao Serviço de Atendimento Móvel de Urgência (SAMU) e/ou aos Bombeiros; 2) não mexer na vítima até a chegada do socorro, devido à possibilidade de agravar o quadro clínico do paciente. 
c. Para realização das compressões torácicas em gestantes a melhor posição para a paciente é a de decúbito dorsal com elevação lateral direta em 30 .

d. As Diretrizes da AHA, para Ressuscitação cardiopulmonar, recomendam a sequência de procedimentos do SBV em C-A-B (compressões torácicas, via aérea, respiração) em pacientes adultos.

e. Na realização de compressões torácicas não há necessidade de se esperar o retorno total do tórax após cada compressão, a fim de realizar, no mínimo, 100 compressões/minuto.

03 - No Manejo da Ressuscitação Cardiopulmonar de um indivíduo adulto em parada cardiorrespiratória, a Diretriz de Ressuscitação Cardiopulmonar recomenda que:

I.A primeira ação a ser executada diante de uma PCR é a avaliação do pulso.

II. Numa vítima adulta em PCR com um socorrista na cena deverão ser executados 15 compressões e 02 ventilações.

III. A avaliação do pulso e da respiração não deve ser menor que cinco segundos, nem maior que 10 segundos

IV. Um erro comum são interrupções prolongadas nas compressões torácicas Está correto o que consta em:
a. II e III, apenas.
b. III e IV, apenas.
c. I, II e III.
d. I e II, apenas.
e. II, apenas.

04 - Os cuidados em paradas cardiorrespiratórias (PCR) devem ser rápidos e corretos. Sobre este assunto temos, EXCETO:

a. A PCR é a interrupção abrupta da circulação sanguínea e dos movimentos respiratórios.

b. É uma súbita falência cardíaca sem possibilidade de manutenção espontânea.

c. As causas podem ser a hipóxia, acidose respiratória e lesões cardíacas.

d. O diagnóstico é feito pela ausência de consciência, ausência de respiração e ausência de pulso central ou periférico.

05 - A detecção e o tratamento precoce das Paradas Cardiorrespiratórias (PCR) no ambiente pré-hospitalar são fatores determinantes para assegurar a sobrevivência, evitando comprometimento neurológico causado por falta de oxigenação cerebral, resultando em sequelas graves. Para que o socorro possa ser prestado de maneira sistematizada ao paciente com PCR súbita, a American Heart Association (AHA), em 2015, desenvolveu os princípios básicos, constituída pela sequência de ações: 1; 2 ; 3; 4; 5 - Preencha as lacunas e a seguir assinale a alternativa correspondente.

a. 1-Pedir ajuda e ordenar trazer o DEA; 2-Avaliar responsividade e respiração; 3Verificar pulso; 4-Realizar compressão e ventilação; 5-Desfibrilação imediata.

b. 1 -Verificar pulso; 2 -Avaliar responsividade e respiração; 3 -Pedir ajuda e ordenar trazer o DEA; 4 -Realizar compressão e ventilação; 5 -Desfibrilação imediata. 
c. 1-Avaliar responsividade e respiração; 2-Pedir ajuda e ordenar trazer o DEA; 3Verificar pulso; 4-Realizar compressão e ventilação; 5-Desfibrilação imediata.

d. 1-Avaliar responsividade e respiração; 2 -Verificar pulso; 3 -Pedir ajuda e ordenar trazer o DEA; 4 -Realizar compressão e ventilação; 5 -Desfibrilação imediata.

06- Acerca das ações executadas na RCP marque a alternativa INCORRETA:

a. Para desobstruir vias aéreas é necessário a manobra de inclinação da cabeça e elevação do queixo

b. O posicionamento das mãos durante uma compressão deve ser na linha intermamilar

c. Em uma PCR no bebê com dois socorristas presentes na cena devem ser executados 30 compressões e 02 ventilações

d. O pulso carotídeo e braquial são exemplos de pulsos centrais respectivamente no adulto e no lactente

e. Vítima em "gasping" deve ser considerado como parada respiratória segundo a última recomendação da AHA

\section{7- Sobre o Desfibrilador Externo Automático (DEA), marque a assertiva FALSA:}

a. Enquanto o DEA carrega, o socorrista deve continuar as compressões

b. Após a desfibrilação, deve-se retornar imediatamente às compressões

c. Vítima com marcapasso implantado, o DEA não é indicado

d. Não existe indicação de avaliação de pulso a cada dois minutos

Figura 2 - Resultados da avaliação do pré-teste aplicada aos profissionais de saúde da Atenção Básica.

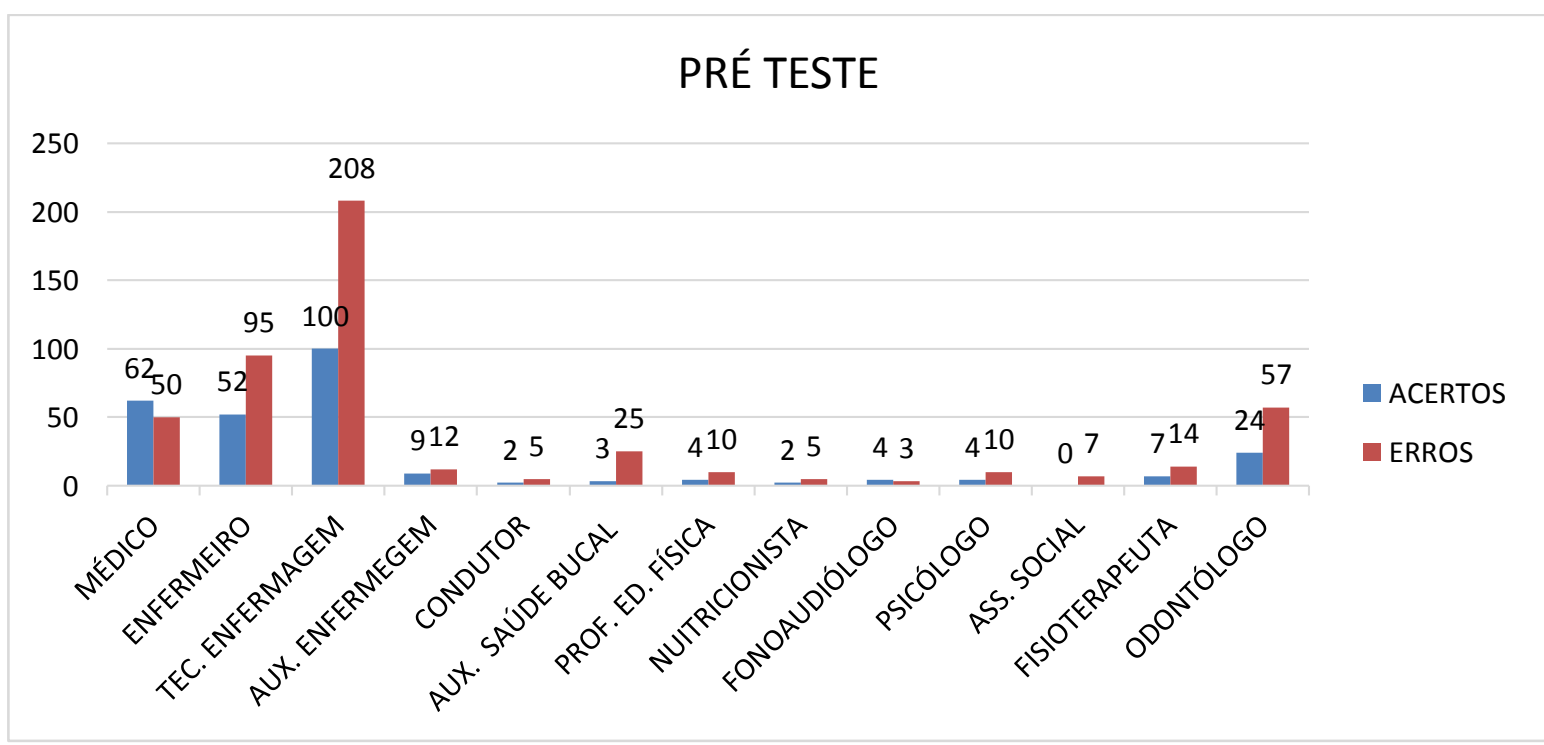


Assim na realização do pré-teste percebeu-se que os erros sobressaíram aos acertos, visto que os profissionais especialmente os técnicos em enfermagem obtiveram um valor referente à 208 erros comparados à 100 acertos, seguido dos enfermeiros com 95 erros comparados a 52 acertos, posteriormente médicos com 50 erros comparados a 62 acertos e os odontólogos com 57 erros comparados a 24 acertos. Os demais profissionais identificados como auxiliar de enfermagem, condutor, auxiliar de saúde bucal, professor de educação física, nutricionista, fonoaudiólogo, psicólogo, assistente social e fisioterapeuta também obtiveram um quantitativo de erros maior que os de acertos.

Figura 3 - Resultados da avaliação do pós-teste aplicada aos profissionais de saúde da Atenção Básica.

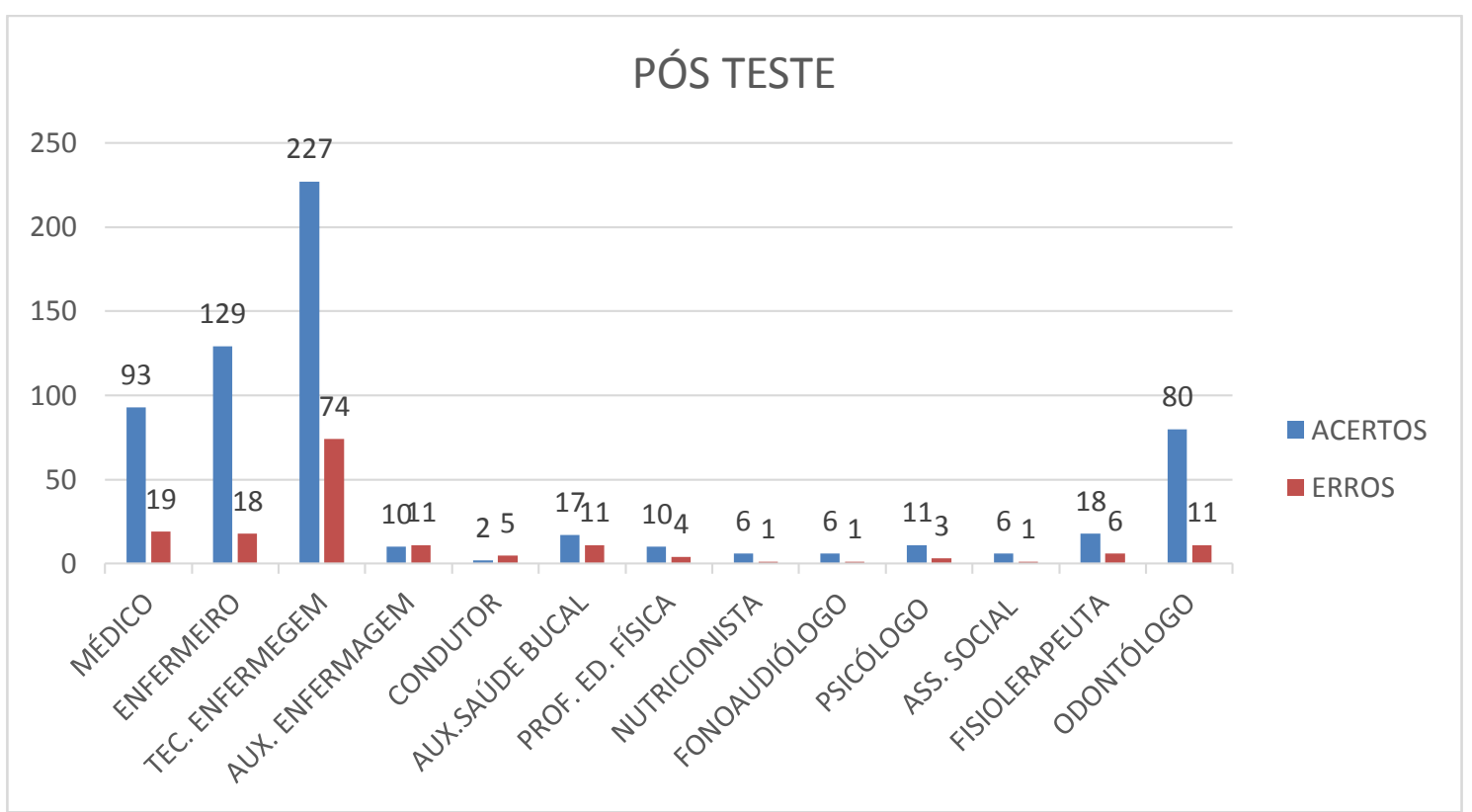


Após realizar a capacitação teóricoprática ministrada pelo Núcleo de Educação Permanente em Urgência do Serviço de Atendimento Móvel de Urgência (SAMU) foi disponibilizado o pós-teste com os mesmos questionamentos do pré-teste, com intuito de observar a efetividade da capacitação ofertada, quantificando as questões corretas e incorretas, e apresentando a correção para estas últimas.

Ao final, foi realizada uma avaliação no intuito de compreender o nível de conhecimento dos participantes acerca da temática proposta. 0 técnico de enfermagem que antes da capacitação obtinha um percentual de erros maior que acertos, nessa segunda tabela do pós-teste apresentou 227 de acertos, comparado a 74 de erros. O enfermeiro 129 comparado a 18, o médico com 93 comparado a 19 e o odontólogo com 80 comparado a 11.

Durante o pós-teste os profissionais conseguiram atingir a notável porcentagem de acertos no questionário, permitindo assim a compreensão de que todos eles partiram de um conhecimento desatualizado/superficial sobre SBV para uma condição de habilitados a prestar essa assistência pré-hospitalar a vítimas de trauma no âmbito da Atenção Básica de Senhor do Bonfim/BA, de maneira a prover um melhor prognóstico no atendimento.

\section{Discussão}

O conhecimento teórico e prático das técnicas de RCP é prioridade e responsabilidade da enfermagem e de todo profissional de saúde, pois todos poderão passar por essas emergências e deverão estar preparados ${ }^{10}$.

Um estudo realizado no Curso Técnico de Enfermagem do Instituto Federal de Pernambuco-campus Belo Jardim, desenvolvido com discentes e estudantes monitores da disciplina de SBV, certificou que a monitoria de SBV do curso técnico de enfermagem expôs vantagens para o processo de ensino e aprendizagem dos discentes envolvidos, em conjunto com o corpo docente, para posterior atuação profissional no mercado de trabalho ${ }^{11}$.

Ainda com relação a enfermagem, estudo realizado com 30 enfermeiros do Serviço de Urgência ressaltou que a performance dos enfermeiros que realizaram formação certificada há menos tempo é relativamente mais adequada quando comparado com enfermeiros com capacitação maior que dois anos atrás. Evidenciando por tanto simulações de breve duração e com periodicidade inferior a um ano ${ }^{12}$.
Em concordância com outra pesquisa realizada com 245 acadêmicos do Curso de Medicina da Universidade Estadual do Pará, mostra que mesmo a PCR sendo um evento corriqueiro no cotidiano médico e na prática clínica, grande parte dos participantes do estudo nunca participou desse episódio. Mesmo com um percentual acima de 50\%, ressalta a importância das lacunas no ensino, precisando serem enfrentadas e avaliadas continuadamente ${ }^{13}$.

De acordo com um estudo realizado com 43 alunos no último ano do curso de Odontologia da Faculdade Morgana Potrich (FAMP), ressalta que os alunos detém um conhecimento insuficiente, sobretudo teórico sobre as emergências médicas em odontologia, fazendose necessário o treinamento apropriado nas manobras em manequins e a inovação do conhecimento durante o curso de graduação, impulsionando um maior conhecimento técnicocientifico e maior confiança caso seja necessário desempenhar manobras de SBV ${ }^{14}$.

Outro estudo constituído por 65 funcionários do campus de uma universidade, demonstrou que os treinamentos precisam ser orientados por uma abordagem teórico-prática por sua maioria evidenciada na literatura. E que as pessoas já preparadas, passem frequentemente por nova capacitação, visto que habitualmente os protocolos são substituídos ${ }^{15}$.

Com relação a outra pesquisa realizada com 3393 estudantes da Escola da Saúde em Natal, Rio Grande do Norte, ressalta a importância na abordagem do assunto no ensino superior, sendo ainda possível perceber que não é suficiente para formação sólida no conhecimento dos alunos, posto que esses acadêmicos serão futuros profissionais, carentes de competências e conhecimento para ocorrências clínicas de urgência e emergência ${ }^{16}$. A simulação mediante o uso de manequins de média fidelidade no decorrer do treinamento se mostrou efetivo para o progresso do conhecimento em SBV ${ }^{17}$.

\section{Considerações finais}

Após a finalização do estudo, foi possível conhecer o nível de fixação dos participantes. Em sua maioria, reconhecem a importância da capacitação profissional para atuarem no SBV em situações de urgência/emergência. Destacando a significância da atualização e da socialização de novas práticas baseadas em evidências. Diante disso espera-se com este estudo, que pesquisas 
futuras possam abordar a capacitação de Suporte Avançado de Vida - SAV, através estratégias pedagógicas com a capacidade de produzir resultados mais amplos, abordando um número cada vez maior de indivíduos, facilitando a difusão de conhecimentos e, com isso, a adoção de técnicas mais eficazes.

Percebe-se a necessidade de expandir esse curso para outras unidades de saúde, visto que estas também estão vulneráveis a ocorrência de situações de PCR. Assim a aplicação do curso se configura como de suma importância não só na melhoria da atuação do SBV dos profissionais, mas também no alcance de maior segurança para toda a sociedade. Esse estudo limita-se por ter sido realizado em um determinado local e em uma realidade sociocultural específica. Portanto, estudos em realidades e culturas diferentes, podem mostrar diferentes resultados

\section{Referências}

1. CLAUDIANO MS, LOPES NNL, SANTOS MVF, LOPES AB, FIORIN BH. Conhecimento, atitude e prática dos enfermeiros da atenção primária em relação a parada cardiorrespiratória. Revista Nursing. 2020; 23(260): 3502-3506.

2. MUSSI FC, TEIXEIRA JRB. Doença isquêmica do coração e masculinidade como fatores de risco cardiovascular. Rev Cubana Enfermer. 2018; 34(2): e1613.

3. CAVALHEIRO CMN, REZANDE MA, NAGIB TC, FONSECA GLM, NETO RMB, ARAGÃO IPB. Prevalência de óbito em via pública por infarto agudo do miocárdio no Brasil em 10 anos. Importância do conhecimento sobre suporte básico de vida. Revista de Saúde. 2020; 11(1): 5563.

4. BARBOSA ISL, MORAES-FILHO IM, PEREIRA BAP, SOARES SR, SILVA W, SANTOS OP. O conhecimento do profissional de enfermagem frente à parada cardiorrespiratória segundo as novas diretrizes e suas atualizações. Rev. Cient. Sena Aires, 2018; 7(2): 117-26.

5. OLIVEIRA KSM, JUSTINO JMR, LINHARES MI, FIGUEIREDO AS, FERREIRA LA, QUEIROZ JC. Suporte básico de vida: capacitação de agentes penitenciários federais para atuação em situações de urgência/emergência. Rev Fund Care Online. 2018; 10(2): 295- 298.

6. MANZATO AJA, SANTOS AB. A Elaboração de questionários na pesquisa quantitativa. Universidade Federal de Santa Catarina, 2012. Disponível em: http://www.inf.ufsc.br/ensino/2012.pdf. 7. SANTOS JLG, ERDMANN ALL, MEIRELLES
BHS, LANZONI GMM, CUNHA VP, ROSS R. Integração entre dados quantitativos $\mathrm{e}$ qualitativos em uma pesquisa de métodos mistos. Texto contexto - enferm. [Internet]. 2017; 26(3): e1590016.

8. IBGE. (2020). Censo de 2020. Disponível em: https://www.ibge.gov.br/cidades-eestados/ba/senhor-do-bonfim.html.

9. CNS.(2012). Resolução № 466, de 12 de dezembro. Disponível em : resolucao-466-cns2012-12-12.pdf (uniara.com.br)

10. PINHEIRO DBS, JUNIOR EBS, PINHEIRO LSB. Parada cardiorrespiratória: vigilância, prevenção e cuidados após PCR. Rev Fund Care Online, 2018; 10(2): 577-584.

11. BELONE JCS, PEREIRA JCN, LIMA AGT, ARAUJO PMOA. A monitoria acadêmica como intervenção teórico prática para estudantes do ensino técnico em enfermagem. Braz. J. of Develop., 2020; 6(11): 86993-87004.

12. PEREIRA JMB, MARQUES MCMP, CANELAS MPP. A Performance dos Enfermeiros em Suporte Básico de Vida. RIASE online, 2019; 5(1): $1760-1774$.

13. BASTOS TR, SILVA MSA, AZEVEDO CP, BORDALLO LES, SOEIRO ACV. Conhecimento de Estudantes de Medicina sobre Suporte Básico de Vida no Atendimento à Parada Cardiorrespiratória. Rev. bras. educ. med., 2020; 44(4): 111.

14. MORETTO MJ, MENEZES LB, BARBIERI G, MENEZES PR. Emergências médicas em consultório odontológico. J Multidiscipl Dent. 2020; 10(1): 9-13.

15. CARVALHO LR, FERREIRA RBS, RIOS MA, FONSECA EOS, GUIMARÃES CF. Fatores associados ao conhecimento de pessoas leigas sobre suporte básico de vida. Enfermería Actual de Costa Rica. 2020; (38): 163-178.

16. GALVÃO DA SILVA BT, ANDRADE ES, PAIVA RM, LUCAS DA SILVA HL, SANTOS WN, LIMA NETO AV. Conhecimento de acadêmicos da saúde sobre ressuscitação cardiopulmonar no suporte básico de vida. Rev Fun Care Online. 2019; 11(4): 957-961.

17. COSTA CRB, MELO ES, REIS RK. Simulação no ensino de emergência para estudantes de enfermagem. Revista Cuidarte. 2020; 11(2): e853. 


\section{Endereço para Correspondência}

Monalisa Batatinha de Castro Silva

Rua Macambira Monte Flores № 257 - Centro.

Campo Formoso-BA - Brasil

E-mail: Monalisabcs89@gmail.com

Recebido em 30/12/2020

Aprovado em 08/12/2021

Publicado em 30/12/2021 